\title{
Formation of Thick Ni-Al Composite Coating on Spheroidal Graphite Cast Iron Substrates by Reaction Synthesis Processing
}

\author{
Tetsuro Kimata $^{1, *}$, Keisuke Uenishi ${ }^{1}$, Akira Ikenaga ${ }^{2}$ and Kojiro F. Kobayashi ${ }^{1}$ \\ ${ }^{1}$ Department of Manufacture Science, Osaka University, Suita 565-0871, Japan \\ ${ }^{2}$ Department of Metallurgy and Material Science, Osaka Prefecture University, Sakai 599-8531, Japan
}

\begin{abstract}
Thick Ni-Al intermetallic coating was fabricated on a spheroidal graphite cast iron by the reaction synthesis processing. In this study, wear property and bonding strength of the coating layer were estimated. Densification of the coating layer was achieved with increasing holding temperature. Wear property of the coating layers was measured by sliding wear test. While coating layers formed with a hot press temperatures from 873 to $1033 \mathrm{~K}$ had superior wear property, the layer fabricated at $873 \mathrm{~K}$ for $900 \mathrm{~s}$ indicated the best wear resistance. This is considered to be caused by higher hardness of $\mathrm{Al}_{3} \mathrm{Ni}_{2}$ compound dispersed in the coating layer. Reaction layer was found out at the interface between the coating layer and substrate. The layer was composed of three different phases which were identified as a $\mathrm{Al}_{7} \mathrm{Fe}_{2} \mathrm{Ni}$ and $\mathrm{FeAl}$ from quantitative EPMA analyses. These layers well bonded the coating layer to the substrate. Mean shear strength of interface was approximately $73 \mathrm{MPa}$ and increased with increasing holding time for reaction synthesis process.
\end{abstract}

(Received August 19, 2002; Accepted December 26, 2002)

Keywords: nickel aluminide (NiAl), coating, reaction synthesis, hot press, cast iron, wear property

\section{Introduction}

$\mathrm{NiAl}$ intermetallic compound possesses attractive properties of low density $\left(5.9 \mathrm{~g} / \mathrm{cm}^{-3}\right)$, high melting point $(1911 \mathrm{~K})$ high strength, good corrosion and oxidation resistance. ${ }^{1)}$ Then it offers new opportunities for developing low density and high-strength structural materials which might be used at temperatures higher than that currently possible for conventional steel-base alloys.

On the other hand, spheroidal graphite cast iron (FCD: JIS G 5502) has many advantages such as high strength and damping capacity resulting from the casting ability and graphite structure, so it is widely used for the frame of machines. Recently, improvement of the surface property involving the wear resistance, high temperature oxidation resistance and corrosion resistance is desired to FCD. There have been many techniques practically applied to the surface modification of materials, such as plating, vapor deposition, metal spraying. However, available methods for FCD are limited because of weak adhesion to substrate or heat affection to substrate.

Reaction synthesis is known as a powder metallurgical technique for obtaining intermetallics like $\mathrm{NiAl}$ and ceramics from a mixture of powders. ${ }^{2-4)}$ Application of this process to a surface modification technique would enable the process temperature to be decreased or the process time to be shorter. ${ }^{5,6)}$ If an $\mathrm{NiAl}$ coating on FCD is obtained, the oxidation and corrosion resistance as well as the elevatedtemperature tribological properties of the substrate will be improved and the method will be a candidate for new surface modification technique of FCD. The purpose of this study is to produce $\mathrm{Ni}-\mathrm{Al}$ compound coating layer on the $\mathrm{FCD}$ substrate and to investigate the microstructure and properties of the NiAl coating.

\section{Experimental Procedure}

Spheroidal graphite cast iron (FCD450) was prepared for substrate. These substrates were cut into a plate of $15 \mathrm{~mm} \times 15 \mathrm{~mm} \times 7 \mathrm{~mm}$. Coating surface was cleaned by polishing with alumina powder followed by rincing with acetone.

Nickel and aluminum powders with $99.9 \%$ purity, average sizes of which were $3 \mu \mathrm{m}$, were mixed into the composition of $\mathrm{Ni}-50$ at $\% \mathrm{Al}$. These powders were die-pressed with a load of $400 \mathrm{MPa}$ for $60 \mathrm{~s}$ to the disc shape compact of $10 \mathrm{~mm}$ in diameter and $0.5 \mathrm{~mm}$ in thickness. The compact was set on FCD substrate and was hot pressed (Fig. 1) under a pressure of $20 \mathrm{MPa}$ at $873,923,973$ and $1033 \mathrm{~K}$ for $900 \mathrm{~s}$ and $3.6 \mathrm{ks}$ in a vacuum of $2.0 \times 10^{-3} \mathrm{~Pa}$ followed by cooling to room temperature. A $0.5 \mathrm{~mm}$ thick coating on the FCD substrate

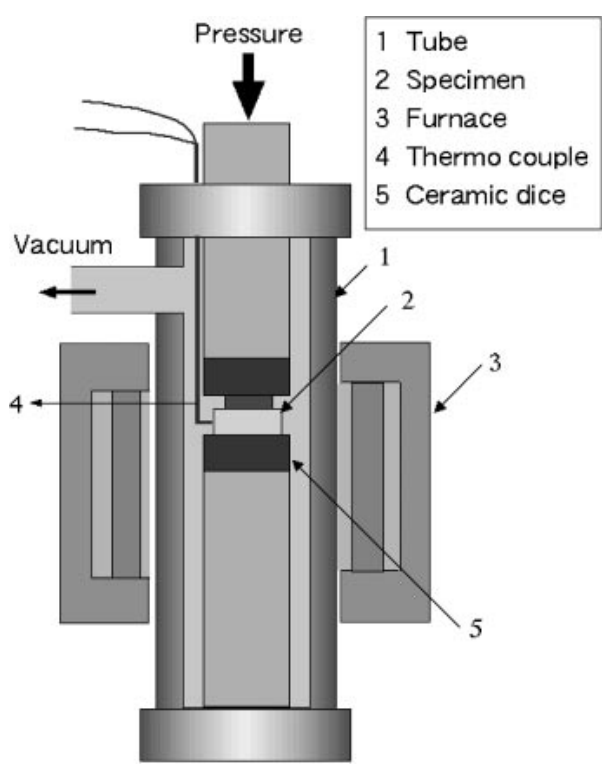

Fig. 1 Schematic illustration of a hot press equipment. 
was obtained. The cross section of the coating layer was examined by means of electron probe microanalysis (EPMA) and optical microscopy (OM). The constituents of the intermetallics in the coating layer was identified by X-ray diffraction analysis. The reactivity of powder compact was examined by differential scanning calorimetry (DSC) with the heating rate of $1.66 \mathrm{~K} / \mathrm{s}$ under an Ar flow atmosphere.

Sliding wear test of the coating layer was conducted using the disc-on-plate type friction machine. The substrate for sliding wear test was cut into a column of $\phi 6 \mathrm{~mm} \times 15 \mathrm{~mm}$. The sliding wear tests were conducted on SS400 disk in air at room temperature. The contact stress was $200 \mathrm{~g}$, and sliding speed was controlled from 2 to $7 \mathrm{~mm} / \mathrm{s}$. Shear test was conducted to evaluate the bond strength of the interface between coating layer and substrate.

\section{Results and Discussion}

\subsection{DSC analyses for the combustion synthesis of compact}

Figure 2 shows DSC trace obtained when a mixed powder of $\mathrm{Ni}$ and $\mathrm{Al}$ with a composition of $\mathrm{Ni}-50 \mathrm{at} \% \mathrm{Al}$ was continuously heated to $973 \mathrm{~K}$ at a heating rate of $1.66 \mathrm{~K} / \mathrm{s}$. The DSC curve showed two exothermic peaks starting from about $850 \mathrm{~K}$ and from about $870 \mathrm{~K}$. Since these peaks occurred at lower temperature than aluminum melting points

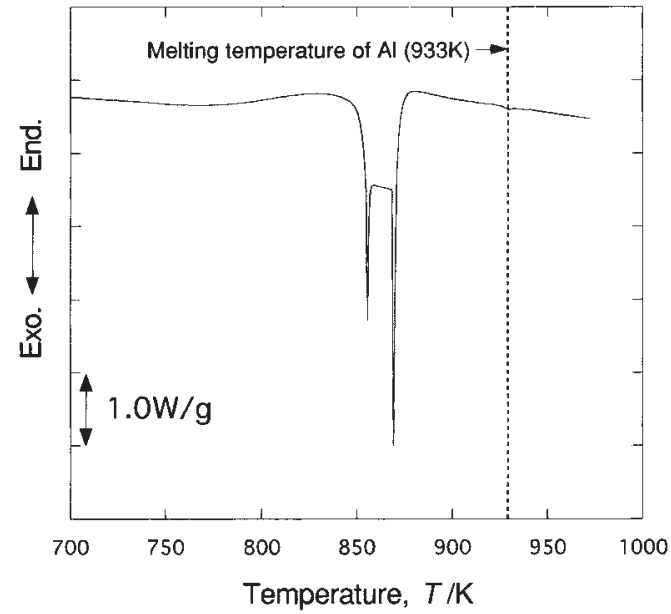

Fig. 2 DSC trace of the compact with a composition of $\mathrm{Ni}-50$ at\% Al. Exothermic peaks appeared at lower temperature than the melting point of Al.

(933 K), solid state interdiffusion is believed to which occurred between the interface of $\mathrm{Ni}$ and $\mathrm{Al}$ particle.

\subsection{Identification of synthesized compounds}

Figure 3 shows cross sections of coating layers sintered by hot pressing at 873 to $1033 \mathrm{~K}$ for $900 \mathrm{~s}$. Under these

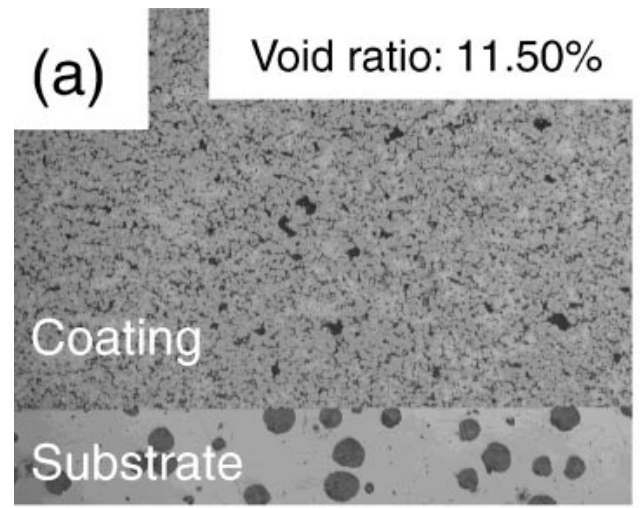

$873 \mathrm{~K}$

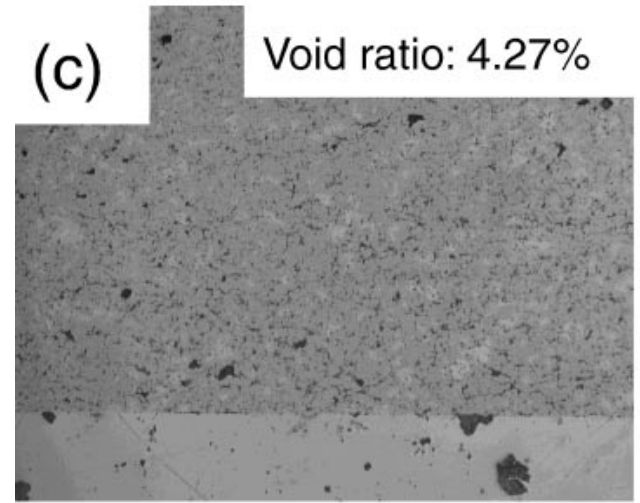

$973 \mathrm{~K}$

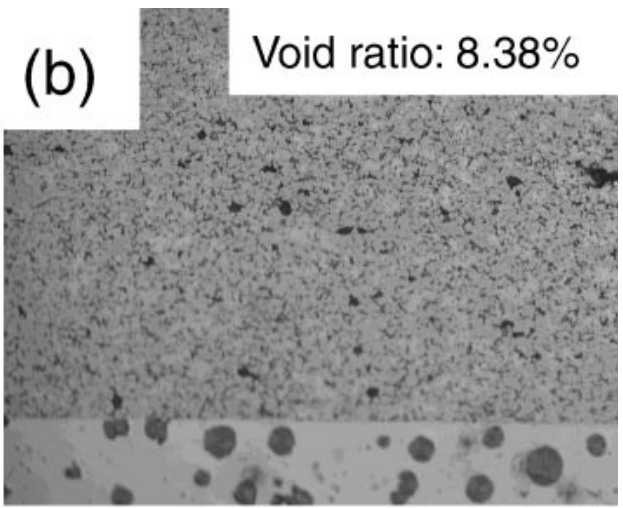

$923 \mathrm{~K}$

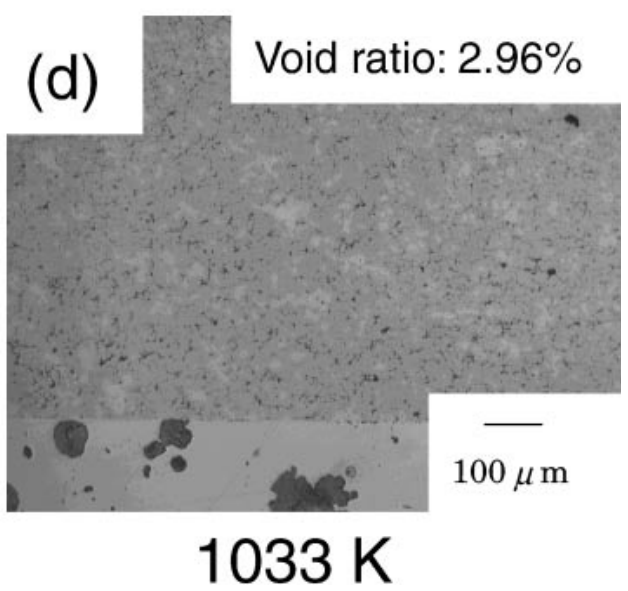

Fig. 3 Microstructures of coating layers fabricated at (a) 873, (b) 923 , (c) 973 and (d) $1033 \mathrm{~K}$ for $900 \mathrm{~s}$. Void ratios in the coating layers decreased with temperature. 


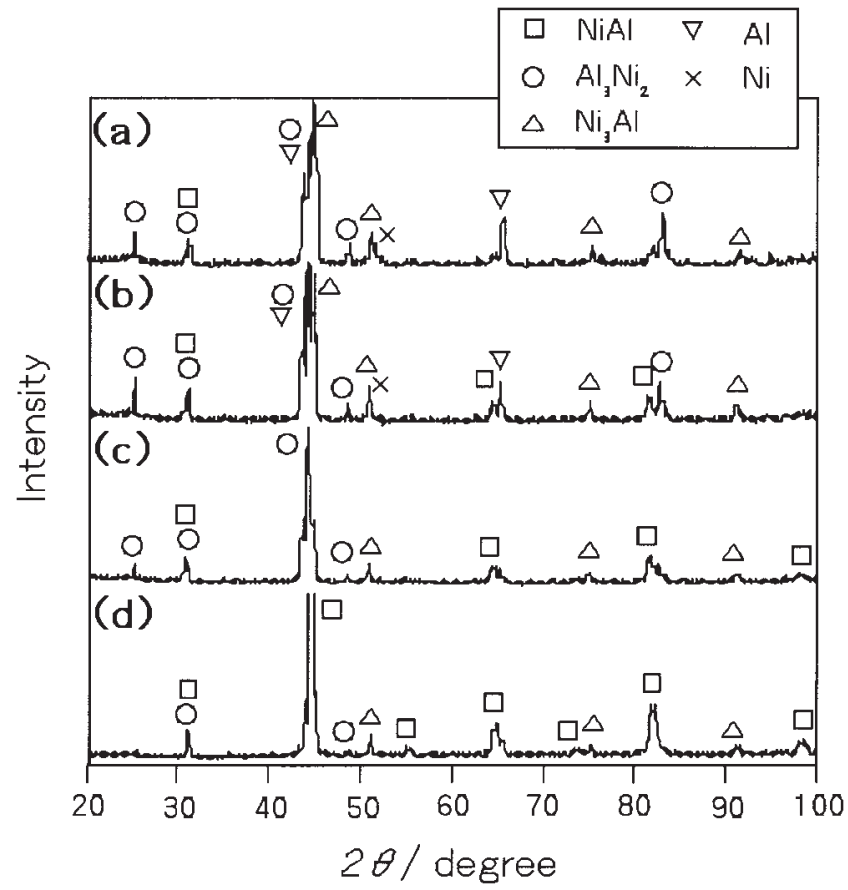

Fig. 4 X-ray diffraction patterns of the coating layer. $\mathrm{Al}_{3} \mathrm{Ni}_{2}$ was mainly formed by heating at (a) $873 \mathrm{~K}$ and (b) $923 \mathrm{~K}$ for $900 \mathrm{~s}$, while NiAl and $\mathrm{Ni}_{3} \mathrm{Al}$ were mainly formed by heating at (c) $973 \mathrm{~K}$ and (d) $1033 \mathrm{~K}$ for $900 \mathrm{~s}$.

conditions, coating layer was formed with no delamination. At $873 \mathrm{~K}$ (a) and $923 \mathrm{~K}$ (b), spherical voids were introduced, which homogeneously distributed in the coating layer. It is considered that solid state interdiffusion occurs between $\mathrm{Al}$ and $\mathrm{Ni}$ particles at the sintering temperatures lower than aluminum melting point, which results in generation of Kirkendall porosity. Void ratio in the coating layer was decreased with increasing hot press temperature (973 K (c) and $1033 \mathrm{~K}(\mathrm{~d}))$.

Figure 4 shows X-ray diffraction patterns of coating layer fabricated at 873 to $1033 \mathrm{~K}$ for $900 \mathrm{~s}$. On the specimens prepared at $873 \mathrm{~K}$ (a) and $923 \mathrm{~K}$ (b), diffraction peaks of $\mathrm{Al}_{3} \mathrm{Ni}_{2}$ mainly detected with weak peaks due to unreacted $\mathrm{Ni}$ and $\mathrm{Al}$. On the specimen prepared at $973 \mathrm{~K}, \mathrm{Al}_{3} \mathrm{Ni}_{2}$ peaks broadened (c), and for the specimen prepared at $1033 \mathrm{~K}$, most peaks were due to $\mathrm{NiAl}$ and $\mathrm{Ni}_{3} \mathrm{Al}$ phases (d). It is reported that if heat treatment temperature was lower than aluminum melting point, solid state interdiffusion occurred to form $\mathrm{Al}$ rich compounds such as $\mathrm{Al}_{3} \mathrm{Ni}_{2}{ }^{{ }^{7)}}$ On the other hand, at higher than aluminum melting point, $\mathrm{NiAl}$ was formed by the reaction synthesis, which was occurred at the interface between liquid state $\mathrm{Al}$ and solid state $\mathrm{Ni}^{7}{ }^{7}$

\subsection{Reaction layer formed in the interface}

Reaction layers were observed at parts of interface in the specimen prepared at $973 \mathrm{~K}$ for $900 \mathrm{~s}$. The mean thickness of the reaction layer was $6 \mu \mathrm{m}$. The reaction layer was not composed of a single layer but divided into two layers (Fig. 5). By EPMA analyses shown in Table 1, the layers A and $\mathrm{B}$ in Fig. 5 were identified as $\mathrm{Al}_{7} \mathrm{Fe}_{2} \mathrm{Ni}$ and $\mathrm{FeAl}$, respectively.

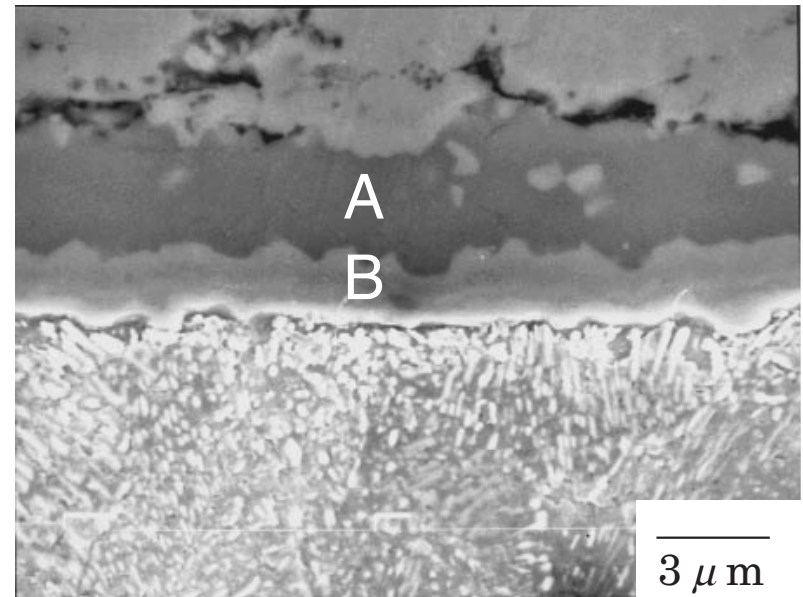

Fig. 5 SEM image of reaction layer formed at the interface between the substrate and coating layer in the specimen fabricated at $973 \mathrm{~K}$ for $900 \mathrm{~s}$.

Table 1 Results of quantitative analyses at the areas A and B shown in Fig. 5.

\begin{tabular}{|c|c|c|c|c|c|}
\hline \multirow{2}{*}{$\begin{array}{c}\text { Analysis } \\
\text { area }\end{array}$} & \multicolumn{4}{|c|}{ Composition, at.\% } & \multirow{2}{*}{$\begin{array}{c}\text { Predicted } \\
\text { phase }\end{array}$} \\
\hline & $\mathrm{Ni}$ & $\mathrm{Al}$ & $\mathrm{Si}$ & $\mathrm{Fe}$ & \\
\hline A & 9.60 & 65.59 & 0.20 & 24.61 & $\mathrm{Al}_{7} \mathrm{Fe}_{2} \mathrm{Ni}$ \\
\hline B & 0.91 & 41.65 & 3.72 & 53.73 & $\mathrm{FeAl}$ \\
\hline
\end{tabular}

\subsection{Hardness of surface layer}

Figure 6 shows the Vickers hardness profiles on the cross section of specimens. The hardness of coating layer on the specimen fabricated at $873 \mathrm{~K}$ for $900 \mathrm{~s}$ was widely scattered ranging from 250 to $500 \mathrm{HV}$ depending each position. This is due to the microstructural inhomogeneity of coating and existence of voids. Higher hardness area contains $\mathrm{Al}_{3} \mathrm{Ni}_{2}$ and lower one contains void or Ni solid solution. The hardness of coating layer fabricated at $1033 \mathrm{~K}$ for $900 \mathrm{~s}$ was almost constant at about $300 \mathrm{HV}$. By the hot pressing at higher temperature, the densification of coating layer and formation of $\mathrm{NiAl}$ was achieved.

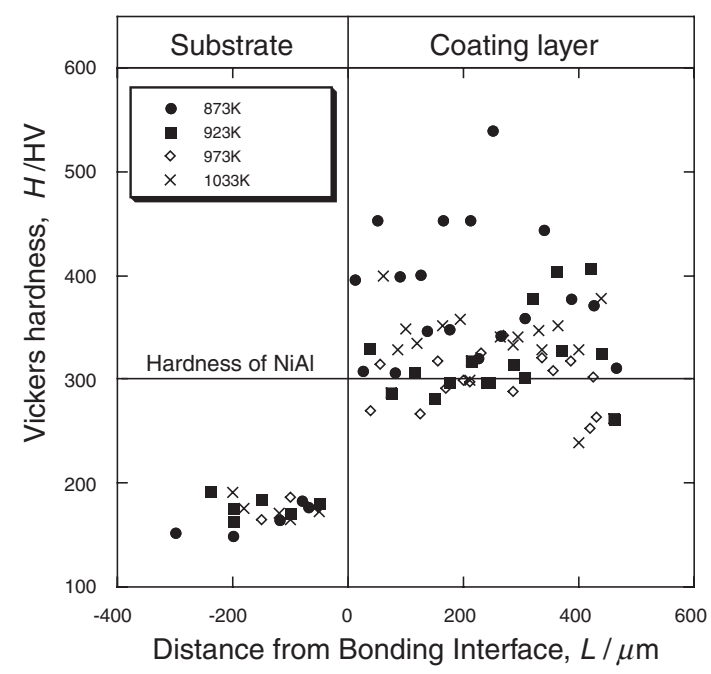

Fig. 6 Vickers hardness distributions of substrates and coating layers fabricated at various temperatures. 


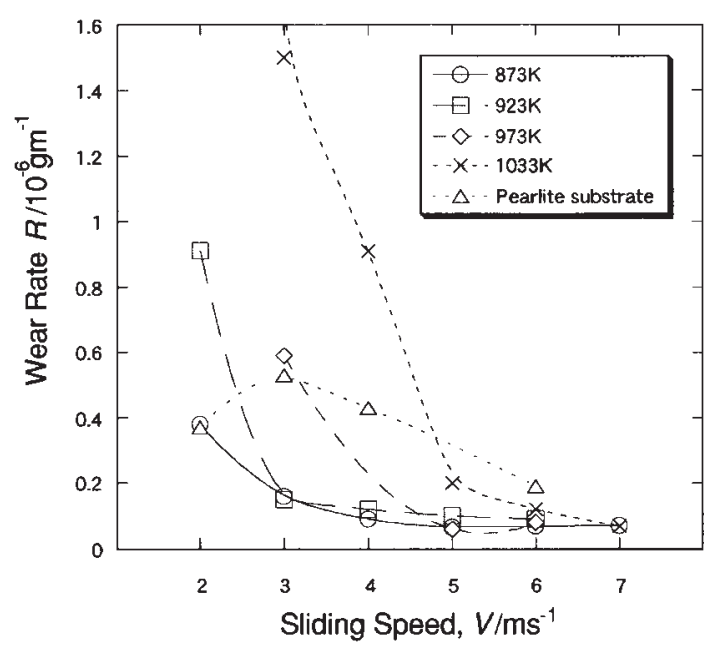

Fig. 7 Effect of sliding speed on wear rate of the coating layers which were fabricated at $873,923,973$ and $1033 \mathrm{~K}$ for $900 \mathrm{~s}$. The layer fabricated at $873 \mathrm{~K}$ indicated best wear resistance.

\subsection{Wear rate property of coating layer}

Figure 7 shows wear rate properties of coating layer. On the specimens fabricated at $873 \mathrm{~K}, 923 \mathrm{~K}, 973 \mathrm{~K}$ and $1033 \mathrm{~K}$ for $900 \mathrm{~s}$, wear rate of coating layer was enhanced with sliding speed $(2-7 \mathrm{~m} / \mathrm{s})$. While coating layers with hot press temperatures of 873 to $1033 \mathrm{~K}$ had superior wear rate property, the layer fabricated at $873 \mathrm{~K}$ for $900 \mathrm{~s}$ indicated the best wear resistance under all sliding speed of 2 to $7 \mathrm{~m} / \mathrm{s}$. The $\mathrm{X}$-ray diffraction analyses (Fig. 4) showed, $\mathrm{Al}_{3} \mathrm{Ni}_{2}$ was formed in the coating layer fabricated at $873 \mathrm{~K}$ for $900 \mathrm{~s}$. It is considered that higher hardness of $\mathrm{Al}_{3} \mathrm{Ni}_{2}$ phase enhanced wear property of the coating layer.

\subsection{Bonding strength of coating material}

Figure 8 shows the results of shear tests on the specimen prepared at $973 \mathrm{~K}$ for $900 \mathrm{~s}$ and $3.6 \mathrm{ks}$. Mean shear strength of interface was approximately $73 \mathrm{MPa}$ (a) and increased with increasing the holding time (b). It is considered that longer heat treatment enables Al to melt sufficiently to give better wettability between coating layer and substrate resulting chemically bonded. Figure 9 shows fracture morphology of

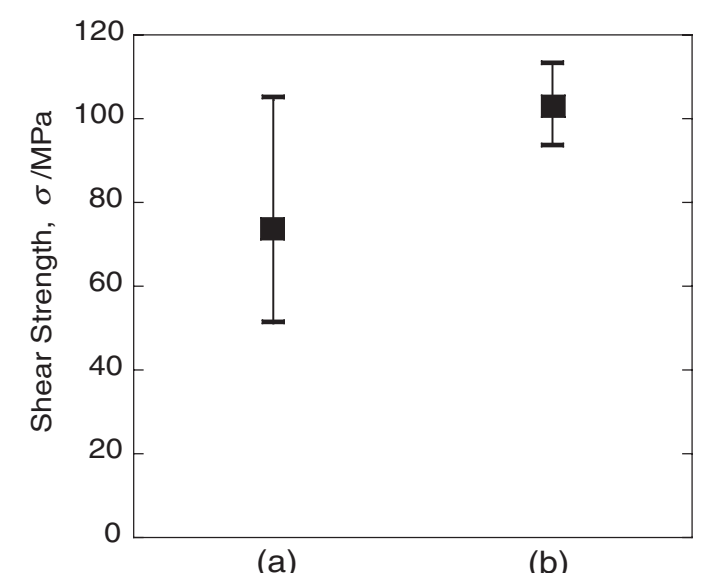

(a)

(b)

Fig. 8 Effect of holding time at $973 \mathrm{~K}$ on shear strength. Hot pressed at $973 \mathrm{~K}$ for (a) $900 \mathrm{~s}$, (b) $3.6 \mathrm{ks}$. Mean shear stress of interface was increased with increasing the holding time.

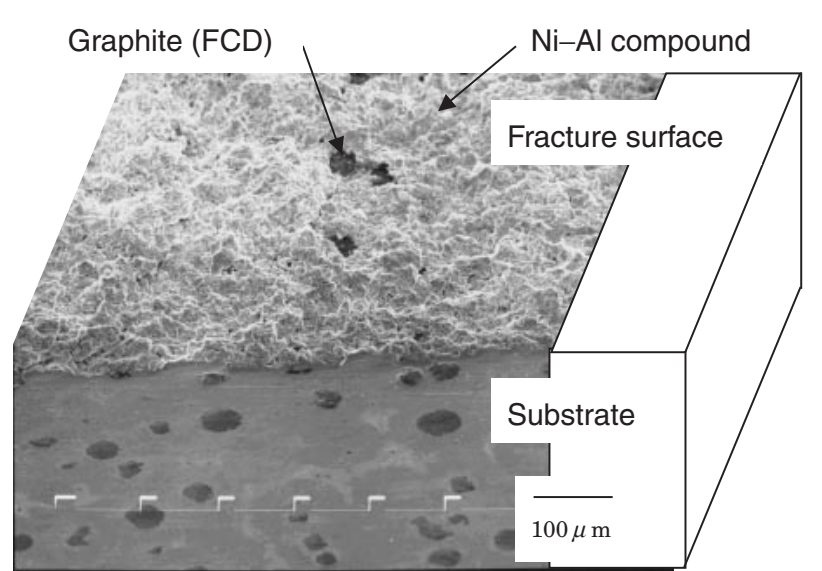

Fig. 9 Fractured surface after shear test on Ni-Al compound/FCD joint fabricated by hot press at $973 \mathrm{~K}$ for 900 s. Fracture was occurred mainly in the inside of coating layer.

bonded material fabricated at $1033 \mathrm{~K}$ for $900 \mathrm{~s}$. Graphites in FCD was observed on the fracture surface. Fracture mainly occurred in the inside of coating layer, which indicate that coating layer was well bonded with substrate. The strength of bonded materials corresponds to the strength of coating layer.

\section{Conclusions}

Applicability of reaction synthesis to a surface modification was investigated. Coating layer with $\mathrm{Ni}-\mathrm{Al}$ intermetallic compound was fabricated on speroidal graphite cast iron. The main results obtained are summarized as follows.

(1) $\mathrm{NiAl}$ and $\mathrm{Ni}_{3} \mathrm{Al}$ were formed by hot press process at 923 to $1033 \mathrm{~K}$ for $900 \mathrm{~s}$, while $\mathrm{Al}_{3} \mathrm{Ni}_{2}$ was formed at $873 \mathrm{~K}$ for $900 \mathrm{~s}$.

(2) Densification was enhanced with increasing hot press temperature and when sintered at $1033 \mathrm{~K}$ for $900 \mathrm{~s}$, void ratio of coating layer was reduced to $2.96 \%$.

(3) Wear rate of coating layer fabricated at $873 \mathrm{~K}$ for $900 \mathrm{~s}$ showed $1.0 \times 10^{-7} \mathrm{~g} / \mathrm{m}$.

(4) Shear joint strength of interface was increased with increasing the holding time at the temperature. When sintered at $973 \mathrm{~K}$ for $3.6 \mathrm{ks}$, mean shear strength of interface was $103 \mathrm{MPa}$. Fracture mainly occurred in the inside of coating layer.

(5) Reaction layer composed of $\mathrm{Al}_{7} \mathrm{Fe}_{2} \mathrm{Ni}$ and $\mathrm{FeAl}$ compound was formed in the interface between coating layer and substrate, bonding strength of which was higher than that of coating layer.

\section{REFERENCES}

1) R. Darolia: JOM 43 (1991) 44-49.

2) A. G. Merzhanov and I. P. Borovinskaya: Dolk. Chem. 204 (1972) 429432.

3) A. Hibino, S. Matsuoka and M. Kiuchi: J. Mater. proc. Technol. 112 (2001) 127-135.

4) A. Biswas, S. K. Roy, K. R. Gurumurthy, N. Prabhu and S. Banerjee: Acta Mater. 50 (2002) 757-773.

5) K. Uenishi, T. Matsubara and K. F. Kobayashi: Z. Metallkd. 90 (1999) 163-167.

6) P. La, M. Bai, Q. Xue and W. Liu: Surface and Coating Technol. 113 (1999) 44-51.

7) K. Morsi: J. Mater. Sci. Eng. A 299 (2001) 1-15. 